\title{
Redes globais de produção: um caminho de análise para a geografia econômica
}

\author{
Juscelino Eudâmidas Bezerra \\ Universidade de Brasília.
} Brasilia. Distrito Federal. Brasill jebgeo@unb.br (1) 0000-0002-2187-2890

\section{revista}

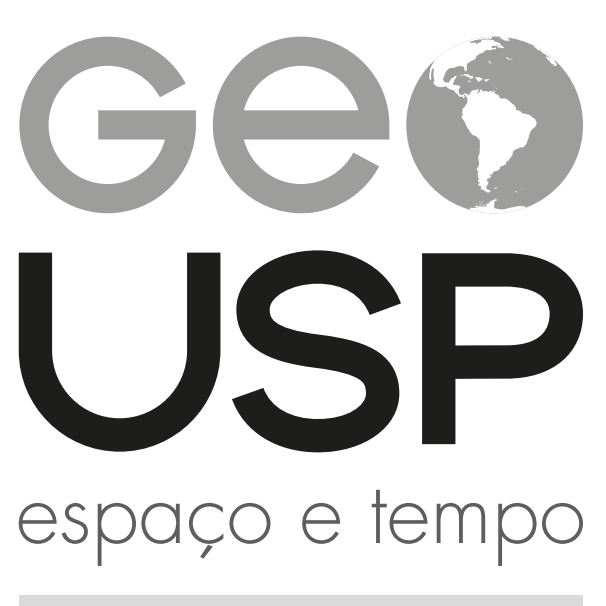

Volume $25 \cdot n^{\circ} 3$ (2021)

ISSN 2179-0892 e-187413

Como citar este artigo:

BEZERRA, J. E. Redes globais de produção: um caminho de análise para a geografia econômica. Geousp, v. 25, n. 3 , e-187413, dez. 2021. ISSN 2179-0892.

Disponível em: https://www.revistas.usp.br/geousp/article/ view/187413. doi: https://doi.org/10.11606/issn.2179-0892. geousp.2021.187413.

\section{(c) $\underset{\text { BY }}{\text { (i) }}$}

Este artigo está licenciado sob a Creative Commons Attribution 4.0 Licence 


\title{
Redes globais de produção: um caminho de análise para a geografia econômica
}

\section{Resumo}

Reconhecer a complexidade da economia global pressupõe um olhar abrangente ao modo como a ciência geográfica pode contribuir para explicar as relações econômicas, sociais e de poder que operam simultaneamente em múltiplas escalas. $\bigcirc$ objetivo do artigo é perscrutar o conceito de redes globais de produção (RGP) como um caminho de análise para a geografia econômica a partir dos estudos pioneiros da Escola de Geografia Econômica de Manchester. A organização das redes globais de produção estrutura-se na questão do valor e em sua trajetória, na caracterização dos atores e em sua diversidade, assim como na configuração de redes e territorialidades. $\bigcirc$ texto também procura entender a dinâmica de organização da economia global a partir de uma análise centrada na agência dos atores, particularmente as empresas líderes, suas estratégias e dinâmicas competitivas, com a finalidade máxima de alcançar o desenvolvimento regional e a superação das desigualdades.

Palavras-chave: Redes globais de produção. Geografia econômica. Economia global.

\section{Global production networks: a path of analysis for economic geography}

\begin{abstract}
The recognition of the complexity of the global economy presupposes a comprehensive look at how geography can contribute to explaining the economic, social and power relations that operate simultaneously at multiple scales. The objective of this article is to explore the concept of global production networks as a path of analysis for economic geography based on the contribution of the Manchester School of Economic Geography, whose studies were pioneered. The organization of global production networks is structured around the question of value and its trajectory, the characterization of actors and their diversity, as well as the configuration of networks and territorialities. It seeks to understand
\end{abstract}


the dynamics of the organization of the global economy from an analysis centered on the agency of the actors, particularly the lead firms, their strategies and competitive dynamics, with the ultimate goal of achieving regional development and overcoming inequality.

Keywords: Global production networks. Economic geography. Global economy.

\section{Redes globales de producción: un camino de análisis para la geografía económica}

\section{Resumen}

Reconocer la complejidad de la economía global presupone una aprehensión completa de cómo la ciencia geográfica puede contribuir para explicar las relaciones económicas, sociales y de poder que operan simultáneamente y en múltiples escalas. El objetivo de este artículo es analizar el concepto de redes de producción global como vía para el análisis de la geografía económica, centrándose en sus ventajas, limitaciones, organización y alcance. Su énfasis reside en la contribución de la Escuela de Geografía Económica de Manchester, cuyos estudios fueron pioneros. La organización de las redes globales de producción se estructura alrededor del tema del valor y su trayectoria, la caracterización de los actores y su diversidad, así como en la configuración de redes y territorialidades. Pretende comprender la dinámica de la organización de la economía global a partir de un análisis centrado en la agencia de los actores, particularmente de las empresas líderes, sus estrategias y dinámicas competitivas, con el fin último de lograr el desarrollo regional y superar las desigualdades.

Palabras clave: Redes de producción global. Geografía económica. Economía global.

\section{Introdução}

No final dos anos 1990 e início dos 2000, um grupo de pesquisadores ${ }^{1}$ da chamada Escola de Geografia Econômica de Manchester, no Reino Unido, iniciou um rico debate sobre as diferentes formas de entender a organização da economia mundial em tempos de globalização.

1 Grupo constituído em grande parte por geógrafos, dentre os quais podemos destacar Peter Dicken, Neil Coe, Jeffrey Henderson, Martin Hess e Henry Yeung. 
A decisão foi influenciada pelo fato de aqueles estudiosos se oporem ao modo como determinadas abordagens teóricas acabavam ocultando processos importantes, sem a devida atenção às interconexões advindas da economia em rede ou à diversidade de atores que passaram a atuar direta ou indiretamente na constituição do mercado. Surgiu, assim, a proposta de analisar as redes globais de produção (RGP) como um modelo heurístico para compreender as geografias de desenvolvimento da economia global.

O conceito de RGP caminha ainda em terreno movediço, devido não só à dificuldade de correlacionar teoria e empiria, como também ao constante processo de modificação da economia em diferentes contextos geográficos. Por essa razão é que se entende tratar-se de uma proposta em construção. $\bigcirc$ objetivo do artigo é examinar o atual estado do conceito pelo procedimento metodológico de revisão bibliográfica, a partir de suas características principais, limitações e possibilidades de análise. Também pretende contribuir para a inserção do conceito de RGP no debate da geografia econômica no Brasil, ${ }^{2}$ área em que as referências a ele, bem como sua aplicação em pesquisas teóricas e empíricas, são ainda escassas. Portanto, este artigo não pretende estabelecer uma recepção do conceito no país, o que pode ser apreciado numa publicação posterior.

Devido ao grande número de publicações que contemplam a discussão sobre RGP, mormente na literatura científica anglo-saxã, tornou-se contraproducente abarcar a totalidade de livros e artigos produzidos especialmente nas duas últimas décadas. Portanto, priorizaram-se as obras pioneiras no debate e os autores geralmente considerados criadores do conceito e/ou que se dedicam mais diretamente ao tema, em especial, os professores Neil Coe e Henry Yeung, responsáveis pelo Global Production Networks Centre, sediado na Universidade Nacional de Singapura.

O artigo está divido em três seções, mais a presente introdução e as considerações finais. Na primeira seção, apresenta-se um breve histórico das abordagens teóricas precedentes à formulação do conceito de RGP Na segunda, são abordados o quadro geral da proposta do conceito, seus aspectos centrais e modelo de organização. Na terceira seção, destacam-se suas vantagens e limitações identificadas pelos próprios proponentes, bem como pelos demais interlocutores acadêmicos.

\section{Perspectivas de análise da organização da economia global: o berço das redes globais de produção}

Pode-se afirmar que a proposta das RGP surgiu da reflexão, da crítica e do aprimoramento de abordagens teóricas anteriores, que apareceram na esteira do debate sobre as teorias da dependência e do sistema-mundo em relação com o desenvolvimento econômico (Gereffi, 2018). Antes de iniciar propriamente a análise da proposta de RGP, é imperioso, portanto, fazer uma breve apresentação das teorias cadeias globais de mercadorias (CGM) e cadeias globais de valor (CGV), assim como das mais recentes, ator-rede (TAR) e capitalismo variegado (CV), tendo em

2 No Brasil, Santos, R. (2011) publicou um artigo sobre o tema e também traduziu o artigo de Henderson et al. (2002) para o português, concorrendo para a divulgação do conceito no Brasil. Ressalta-se ainda a criação do Grupo de Pesquisa do CNPq Governança, Sistemas Agroalimentares e Redes Globais de Produção, em 2015, no Departamento de Geografia da Universidade de Brasilia (UnB) sob minha coordenação. 
vista sua importância como berço de origem da RGP e a existência, muitas vezes, de pontos de aproximação e de distanciamento entre esta abordagem e as teorias citadas.

No início da década de 1990, havia um interesse renovado para compreender a configuração de uma nova divisão internacional do trabalho num padrão geograficamente extenso e disperso, com uma estrutura de organização industrial de empresas densamente conectadas. Os trabalhos de Gereffi, Korzeniewicz, M. e Korzeniewicz, R. (1994) e Gereffi (2018) inauguram uma nova interpretação, ao sugerir uma abordagem que pudesse melhor avaliar as mudanças na organização espacial da produção e do consumo na economia mundial. Intentando uma análise com base em "um conjunto de redes interorganizacionais agrupadas em torno de uma mercadoria ou produto, ligando domicílios, empresas e Estados um ao outro no interior de uma economia mundial" (Gereffi; Korzeniewicz, M.; Korzeniewicz, R., 1994, p. 2), a proposta recebeu o nome de CGM.

Os autores sinalizam que estudos da perspectiva da CGM permitem evidenciar como a produção, a distribuição e o consumo são transformados pelas relações sociais, bem como estabelecer mais claramente os vínculos entre as macro e microescalas. No que concerne às escalas espaciais, a CGM se distancia do enfoque predominante da teoria do sistema-mundo referendada nas categorias espaciais: núcleo, semiperiferia e periferia. Logo, favorece uma análise mais flexível, buscando identificar processos que ocorrem acima e abaixo do nível Estado-nação. $\bigcirc$ enfoque da CGM destaca, igualmente, a necessidade de se voltar "não apenas para a distribuição geográfica dos arranjos transnacionais de produção, mas também para o seu escopo organizacional" (Gereffi; Korzeniewicz, M.; Korzeniewicz, R., 1994, p. 96). Busca, portanto, compreender as ligações entre os vários agentes econômicos - como fornecedores de matéria-prima, fábricas, comerciantes e varejistas - para compreender os elementos que favorecem a estabilidade e a mudança nos elos da cadeia.

De acordo com Gereffi, Korzeniewicz, M. e Korzeniewicz, R. (1994, p. 97), a CGM foi elaborada inicialmente com base em três dimensões: (1) estrutura de insumo-produto ("conjunto de produtos e serviços ligados entre si em uma sequência de atividades econômicas que agregam valor"), (2) territorialidade ("dispersão espacial ou concentração de redes de produção e distribuição, compostas por empresas de diferentes tamanhos e tipos") e (3) estrutura de governança ("relações de autoridade e poder que determinam como o material financeiro e os recursos humanos são alocados e fluem dentro de uma cadeia"). Raikes, Jensen e Ponte (2000, p. 393) lembram que Gereffi incorporou, mais tarde, uma quarta dimensão - a estrutura institucional para mostrar como o contexto político local, nacional ou internacional modifica a participação de um país em cada estágio da cadeia de valor.

No ano de 1999, foi realizado um workshop no Instituto de Estudos de Desenvolvimento da Universidade de Sussex, no Reino Unido, com o título "Espalhando os ganhos da globalização". $\bigcirc$ objetivo do evento era o de desenvolver uma agenda de pesquisas que pudesse aprimorar o entendimento das ligações macro (global), meso (indústria e país) e micro (empresa e comunidade). Como resultado das discussões, foi proposta uma nova abordagem conceitual denominada CGV. Para Kaplinsky e Morris (2001, p. 4), ela "descreve toda a gama de atividades que são necessárias para trazer um produto ou serviço, através das diferentes fases de produção". Ainda segundo 
esses autores, a CGV tem a vantagem de superar a visão setorial estática e limitada, atada à visão tradicional de uma economia imobilizada. Busca-se, então, entender a dinamicidade das atividades econômicas extrapolando a análise apenas do setor de produção para avaliar igualmente as relações intra e intersetoriais e os aspectos formais e informais das atividades.

Ao destacar que as atividades econômicas são ao mesmo tempo internacionais no seu escopo e globais em sua organização, Gereffi et al. (2001, p. 2) mostram que "a perspectiva da cadeia de valor é um meio eficaz de conceituar as formas que esta integração leva. Ela muda o foco da produção sozinha para toda a gama de atividades desde a concepção até o marketing" .

De acordo com Gereffi (2018, p. 16), adotou-se o nome cadeias globais de valor por várias razões. A primeira foi a necessidade de se distanciar da expressão commodity chains, para não se confundir, potencialmente, com a discussão de Wallerstein, na teoria do sistema-mundo. Outra razão foi o fato de que a palavra commodity associa-se geral e indiscriminadamente a produtos primários como mercadorias agrícolas, petróleo bruto ou minerais não processados, mas não a bens manufaturados e serviços. Por fim, o termo valor, próximo da ideia de valor agregado, enfatiza seu processo de criação, captura e retenção nas cadeias de abastecimento.

Coe, Dicken e Hess (2008) ressaltam que a proposta das CGV deu maior ênfase ao tema da governança, substituindo o modelo binário (cadeias dirigidas por produtores e cadeias dirigidas por compradores) por um modelo mais complexo, muito embora ainda limitado por uma concepção estreita das relações de poder e suas assimetrias no interior das redes de produção.

A teoria ator-rede (TAR) tem origem nas reflexões desenvolvidas eminentemente na França e na Inglaterra por professores como Bruno Latour (2012), Michel Callon (1986) e Jown Law (2003). Sua principal influência pode ser encontrada em Michel Focault, Gilles Deleuze, Félix Guatarri e Michel Serres (Dicken et al., 2001; Jóhannesson; Bæerenholdt, 2009). Não obstante o fato de o intento ser mais teórico do que prático ou de aplicação, a TAR foi incorporada aos estudos econômicos para melhor compreender a organização da economia por meio das redes, compostas por atores humanos e não humanos (elementos naturais e artefatos técnicos). No plano das pesquisas realizadas pela geografia econômica, Dicken et al. (2001, p. 104) destacam o fato de a TAR permitir ao pesquisador analisar a constituição e reformulação das organizações econômicas mediante o rastreamento das inúmeras formas de engajamento entre um conjunto de atores em rede.

Por fim, outra perspectiva teórica importante e que viria a fortalecer a elaboração da proposta das RGP é o conceito de CV. Como o próprio termo indica, propõe a reflexão sobre a possibilidade de pensar o capitalismo como um sistema que apresenta distintas variações, modelos organizacionais e formas institucionais em contextos geográficos particulares. Como as variações do capitalismo são muito influenciadas pelo contexto institucional dos Estados-nação, a proposta acabou sendo conveniente para a geografia econômica, por haver explicitado a existência de fundamentos institucionais próprios que ajudaram a desenvolver o capitalismo em muitos países.

De acordo com Peck e Theodore (2007), a análise do CV se coaduna com a abordagem já feita pela geografia econômica, ao enfatizar a contínua variabilidade geográfica do capital, ao refutar a teleologia do mercado e ao catalogar as formas institucionais resilientes nas escalas local e nacional. Os autores indicam ainda a importância de valorizar a perspectiva da Geografia, 
que, devido a seu enfoque multiescalar, permite "desconstruir, desagregar ou mesmo descartar 'modelos' nacionais como arquétipos super generalizados, optando por trabalhar mais próximo do solo - na escala subnacional ou por meio de redes transnacionais" (Peck; Theodore, 2007, p. 759).

Ao fim e ao cabo, como salientam Coe, Dicken e Hess (2008), as abordagens supracitadas têm muitos pontos comuns com a das RGP, como se verá no próximo tópico. Todas compartilham de um mesmo pressuposto ontológico, ou seja, baseiam-se nas variantes de cadeia/ rede e, do ponto de vista epistemológico, voltam-se para a análise da dinâmica social e de desenvolvimento do capitalismo contemporâneo no nexo global nacional-local.

\section{A organização das redes globais de produção}

Num dos primeiros artigos sobre o tema, Henderson et al. (2002, p.153) propuseram inicialmente definir as RGP como o nexo globalmente organizado de funções interligadas e operações de empresas e instituições não empresariais por meio das quais bens e serviços são produzidos, distribuídos e consumidos. As redes de produção contemporâneas caracterizam-se por sua maior complexidade e extensão geográfica. Elas têm a capacidade de cruzar as fronteiras nacionais e criar descontinuidades territoriais, ao mesmo tempo em que refletem especificidades locais como formas de enraizamento.

Por se tratar de uma abordagem elaborada eminentemente por geógrafos, há uma clara predileção pelo conceito de rede ao de cadeia. A noção de cadeia parte da análise vertical, linear, unidirecional e sequencial (adição de valor em cada etapa) da organização da economia global (COE; DICKEN; HESS, 2008). Logo, tem uma limitação natural frente ao desafio de retratar fidedignamente o caráter relacional do funcionamento da economia. Já as redes, como ressalta Peter Dicken (2010, p. 36), "são estruturas extremamente complexas com complicadas ligações horizontais, verticais, diagonais - formando treliças multidimensionais, de várias camadas de atividade econômica". Como resultado do enfoque no conceito de redes, com suas formas de enraizamento e as interações entre os agentes econômicos, a compreensão das RGP advém da constatação de que elas são profundamente multiatoriais e multiescalares, perpassadas por relações assimétricas de poder. São esses os atributos que podem melhor resumir as críticas às propostas anteriores.

Após a primeira década de discussões sobre a proposta das RGP, foram consideráveis os eventos científicos e as publicações de periódicos, livros e enciclopédias sobre o tema. Em 2015, os geógrafos Neil Coe e Henry Yeung, principais criadores e entusiastas do conceito, publicaram o que pode ser considerado o primeiro livro dedicado exclusivamente a ele, com o título Global Production Networks: Theorizing Economic Development in an Interconnected World. Desde então, a publicação tornou-se referência fundamental para a análise conceitual da proposta, uma vez que apresenta a discussão sistematizada e amadurecida, o que também justifica a citação recorrente da obra ao longo do artigo.

No livro, os autores estabeleceram uma primeira categorização acerca dos estudos iniciais sobre RGP e os aperfeiçoamentos da proposta. Por essa razão, propuseram um corte analítico designando uma primeira abordagem conceitual (RGP 1.0), anterior à publicação do livro, e uma segunda (RGP 2.0), revisada e atualizada, procurando responder a críticas como as 
formuladas por Sunley (2008), sobre a falta de um esquema analítico baseado numa explicação causal com respaldo e aplicabilidade empírica.

De modo geral, na comparação entre a RGP 1.0 e RGP 2.0, não há uma ruptura no que tange às bases do conceito. Entretanto, na RGP 2.0 há um esforço maior para ressaltar um conjunto de ações que expressam as dinâmicas competitivas e as estratégias específicas de cada ator. Em proposta mais recente, defendida por Coe e Yeung (2015, p. 1-2), as RGP são o resultado de um "arranjo organizacional, composto por atores econômicos e não econômicos interconectados, coordenados por uma empresa líder global, produzindo bens ou serviços em várias localizações geográficas para os mercados mundiais". Tendo em vista esses aspectos, como se organizam as RGP? Para responder a essa pergunta, é preciso examinar as dimensões de análise dessa abordagem. Ela pressupõe/postula a existência de determinados fatores a ser considerados, particularmente o valor, os atores, as redes e sua territorialidade. Segue-se a apreciação de cada um dos aspectos constituintes das RGP, de modo a explicitar seu modelo de organização.

Para Coe e Yeung (2015, p. 35), as redes se orientam prioritariamente para a criação, o aprimoramento e a captura do valor. $\bigcirc$ valor é compreendido tanto na sua perspectiva de cariz marxista - segundo a qual ele se origina da mais-valia extraída do processo de produção que converte força de trabalho em produtos e serviços a serem trocados por valor maior do que o do trabalho neles incorporado - quanto sob a visão de que o valor é fruto das várias formas de renda econômica que podem ser obtidas a partir do mercado no interior das RGP.

É importante ressaltar que o termo "produção", que compõe o nome da proposta, de modo algum se restringe às atividades industriais, mas compreende uma variada gama de outras atividades, tais como extração de recursos naturais e prestação de serviços, igualmente envolvidas na criação, no aprimoramento e na captura do valor.

As "trajetórias da captura do valor" mostram como as empresas podem apreender os ganhos de sua inserção nas RGP e o impacto no desenvolvimento territorial. No processo de aprimoramento do valor, a inovação tecnológica e o conhecimento são centrais. Outro fator importante é a capacidade que têm determinados atores (extrafirma inclusive) de reter e/ou capturar o valor.

As considerações sobre os atores que participam direta e indiretamente da constituição das RGP partem da necessidade de saber quem está envolvido nas atividades de valor e como esses agentes as coordenam, controlam e governam. Essa tarefa não pode ser cumprida sem que se amplie o escopo de análise para incorporar um conjunto de atores econômicos e não econômicos, reunidos em três grupos principais: as empresas, os atores extrafirma e os atores intermediários (Coe; Yeung, 2015, p. 38).

As empresas podem ser descritas com base em seu papel e sua função no interior da rede de produção. São identificadas pela sua liderança (empresa líder) e pela plasticidade de sua função, ora como parceira estratégica, uma fornecedora (especializada e/ou genérica), ora como empresa cliente. É imprescindível destacar que, na perspectiva das RGP, as empresas podem desempenhar múltiplos papéis funcionais. 
O enfoque nas empresas líderes e, em especial, nas corporações transnacionais e sua plasticidade funcional está em consonância com a visão de Dicken (2010, p. 125), quando lembra que as empresas transnacionais se tornaram as principais formadoras da economia global.

Por empresa líder deve-se entender aquela que, por seu poder específico e sua capacidade organizacional, consegue exercer o controle de mercado pela definição do produto (branding, tecnologia e know-how) e por sua comercialização (receita ou participação). A forma como as empresas líderes exercem o poder permite-lhes influenciar as decisões de investimentos, bem como as que envolvem outros atores da rede.

A importância das empresas transnacionais fica notória quando se observa que elas compõem a grande maioria dos exemplos de empresas líderes em diferentes setores, tais como Apple, Google, Nike, Toyota, Hilton, British Airways, Walmart e Nestlé. Todas desempenham inúmeros papéis funcionais e têm graus específicos de expertise para adaptar sua atuação a contextos geográficos particulares, operando parcerias ao invés de proceder no velho esquema cliente-fornecedor.

A despeito de a análise da perspectiva das RGP focalizar preferencialmente as empresas, ela renova a leitura da organização da economia dando mais importância dada aos atores extrafirma, visto que não se pode compreender o funcionamento atual da economia sem deixar de considerar a ação de determinados grupos que influenciam sobremaneira a organização e a operacionalização das redes de produção.

Os atores extrafirma compreendem instituições e grupos estatais e não estatais que se relacionam com as empresas na criação, no aprimoramento e na captura do valor no interior das redes, entre os quais se destacam o Estado, organizações internacionais, grupos trabalhistas e de consumidores e organizações da sociedade civil (Coe; Yeung, 2015, p. 47).

A participação do Estado na organização das redes econômicas não é nenhuma novidade. No entanto, é possível afirmar que seu papel tem se transformado nos últimos anos, com efeito da organização das RGP (Smith, 2015). Ele continua sendo o principal responsável na promulgação e regulamentação de leis que interferem diretamente na organização da economia, mas não é mais o único ator a empreender iniciativas nesse sentido. Segundo o quadro identificado por Jessop (2016), além de não ser mais a âncora da regulação política, o Estado deve ser entendido pelos processos simultâneos de sua de-hierarquização, heterarquização da arena política internacional, recalibração do poder do Estado e desestatização da política.

Malgrado seu papel relativo na organização das redes e da regulação política, ele é ainda um ator ativo e, frequentemente, uma figura preponderante na mobilização do mercado, porquanto aporta vultosos recursos públicos em forma de crédito. Muitas vezes, o Estado se confunde com as próprias empresas, como no caso dos empreendimentos de que é o proprietário e que exercem papel de liderança; veja-se o exemplo da Petrobras no setor de exploração de petróleo.

Coe e Yeung (2015, p. 48) chamam atenção para as situações em que o Estado promove determinadas empresas por meio de uma política industrial que favorece concessões, empréstimos e benefícios fiscais. Outrossim, estimula atividades de pesquisa e desenvolvimento, o que garante um maior aprimoramento do valor para estimular o desenvolvimento da economia nacional, refutando, portanto, a ideia enganosa do protagonismo exclusivo do capital privado na geração de valor a partir do investimento em tecnologia e pesquisa, como bem demonstrou 
Mazzucato (2014), na perspectiva do Estado empreendedor. É exatamente o contexto geográfico que vai ajudar a definir o tipo de ação empreendida pelo Estado.

Outro ator extrafirma importante são as organizações internacionais. A concretude das RGP pressupõe a possibilidade de uma maior extensão geográfica, o que ajuda a definir não somente a operacionalidade das trocas comerciais de produtos e serviços, mas também algo que é mais desafiador: a coordenação política dos atores envolvidos e o jogo de poder estabelecido entre empresas nacionais e multinacionais que operam em diferentes países.

Os exemplos mais expressivos de organizações internacionais que participam ativamente na organização das RGP são a Organização Mundial do Comércio (OMC) e o Fundo Monetário Internacional (FMI). Esses órgãos são responsáveis pelo incremento do poder regulatório, cujo aspecto mais visível é a definição de mecanismos envolvendo ações anti-dumping, proteção de propriedade intelectual, liberalização do setor financeiro, disciplina fiscal das finanças públicas etc.

Outro tipo de organização internacional que ganhou relevância no contexto das redes são as instituições dedicadas ao desenvolvimento de códigos de conduta para condições de trabalho (por exemplo, a Organização Internacional do Trabalho) e também para suporte aos países em desenvolvimento que participam da economia globalizada, como a Conferência das Nações Unidas sobre Comércio e Desenvolvimento (UNCTAD).

No campo dos atores extrafirma e que também se caracterizam por ser não estatais, destacam-se os grupos trabalhistas, os de consumidores e os demais conjuntos frutos da organização da sociedade civil. Coe e Yeung (2015, p. 49) mencionam a importância de ponderar a ação de organizações trabalhistas, que podem interferir diretamente na cogovernança das atividades de valor pelas empresas inseridas nas redes de produção. Vejam-se, por exemplo, os países e regiões onde os sindicatos e a regulação do trabalho são mais expressivos, em contraposição a outros onde as organizações trabalhistas são fracas ou pouco atuantes.

Em sintonia com a ação dos trabalhadores, a atuação dos grupos de consumidores tem concorrido de forma decisiva na redefinição da relação entre empresas e consumidor final. Tais grupos ajudam a traduzir as preferências dos consumidores em pressão coletiva dirigida tanto às empresas quanto ao Estado. Barrientos (2013, p. 47) chama atenção para os aspectos do consumo ético e da ética do cuidado, como características fundamentais que influenciam as escolhas dos consumidores. Essas preocupações não se manifestam mais somente na esfera doméstica e da produção, mas também no domínio comercial. Daí a necessidade das empresas de ampliar conhecimento e habilidades para coordenar seu engajamento com os consumidores e se adaptar às mudanças de parâmetro. $\bigcirc$ veículo de ação por meio da linguagem de consumo traduz-se, por exemplo, na prática simultânea de boycott (punição aos negócios por comportamento desfavorável) e de buycott (apoio aos negócios com comportamento desejável) (Neilson, 2010).

Por fim, entre os principais atores que participam das RGP, destacam-se os atores intermediários. Eles formam os chamados novos governantes globais, cuja capacidade de interferir na organização das redes é crescente, tendo em vista que operam na interseção de múltiplas redes, como um tecido conectivo (Coe, 2021). Entre os atores intermediários mais importantes, destacam-se os intermediários financeiros, os provedores logísticos e os ligados à criação de standards (Coe; Yeung, 2015, p. 52). 
Os serviços financeiros constituem hoje um elemento crucial na consecução das atividades dos conglomerados empresariais. Nenhum grande grupo que deseje operar em mercados globais pode prescindir dos serviços de investimento, projeção de mercados e avaliação de risco, entre outros. Ao mesmo tempo em que o setor financeiro ganhou destaque nas transações econômicas, ele se fortaleceu com a criação de agências de classificação de risco de crédito, as chamadas agências de rating, cujo poder reflete bem o significado de uma nova estrutura de governança, porquanto detêm a capacidade de derrubar governos e/ou aniquilar fortunas a cada anúncio de decisão por elas tomada.

Os provedores logísticos ampliaram igualmente sua importância na participação em RGP devido à diversificação de seus papéis funcionais. Cabe a eles não só realizar os processos de planejamento, implementação e gerenciamento, mas também responsabilizar-se pelo estoque de matérias-primas, de componentes e de produtos acabados, da produção ao consumo (Coe; Yeung, 2015, p. 53).

Os intermediários envolvidos com standards são aqueles que se ocupam da criação, aplicação e harmonização de protocolos de conhecimentos e especificações codificados de bens e serviços. O desdobramento mais evidente da importância dos standards foi exatamente o surgimento de um mercado inteiramente novo de empresas de consultorias voltadas para a aplicação de padrões e de demais prestadores de serviços associados, cuja função é intermediar a relação entre os vários atores de uma rede de produção.

Ponte, Gibbon e Vestergaard (2011, p. 1) definem standards como um "modelo pelo qual pessoas, objetos ou ações (incluindo os próprios regulamentos governamentais) podem ser julgados e comparados e que fornecem uma linguagem comum para avaliadores, avaliados e seus públicos". Os autores lembram ainda que a criação de normas e padrões era apenas uma forma de estandardizar questões técnicas, metrológicas e de compatibilidade, com o intuito de simplificar, uniformizar e especificar objetos e processos.

Mais do que apenas criar constrangimentos, o estabelecimento de normas também permite interações pela construção de uma linguagem comum e a promoção de meios de comunicação. $\bigcirc$ resultado é a assunção de um sistema de normas, valores e convenções que são revisáveis e negociáveis, ao contrário de absolutas (Ponte; Gibbon; Vestergaard, 2011). A definição de normas como forma de controle ajudou a consolidar uma perspectiva de governança entendida como normalização. Teoricamente, esse entendimento dialoga com a chamada teoria da convenção. De acordo com Wilkinson (2002), o mérito dessa teoria é "tornar visível o mundo de valores escondido por trás das normas e técnicas e identificar os foros de debate em torno de standards como o lócus privilegiado de negociação de interesses e valores".

No âmbito da Geografia, é importante resgatar o interesse pela relação entre norma e uso do território quando, como ressalta Milton Santos (2002, p. 232), a regulação da economia e do território se impõe com mais força por meio de ações normadas e objetos técnicos. Pois, com o aprofundamento da divisão internacional do trabalho, surgem novas complementariedades, e o processo produtivo, disperso e fragmentado geograficamente, necessita ser vigiado, acompanhado e regulado por ordens formais e informais, a depender dos agentes envolvidos. 
Antas Jr. (2015) aprofunda a discussão sobre o território como norma e o território normado e, principalmente, acerca da densidade normativa dos territórios.

Tais discussões têm estreita vinculação com a ação normada preconizada, por exemplo, pelos standards, e certificações privadas, de terceira parte, muitas vezes tidas como voluntárias, mas na prática, mandatórias, e que não estão prescritas no terreno das normas jurídicas de um Estado-nação, muito menos de órgãos supranacionais. As certificações acabam por determinar um conjunto de práticas que devem ser seguidas por regiões, empresas e territórios nos quais se dá a produção de bens e serviços por trabalhadores e mesmo por governos, numa relação hierárquica de comando, geralmente do norte para o sul global, diagnosticado nos estudos de Hughes (2007) e Bezerra (2017, 2018) para o setor agroalimentar.

Após apresentar a composição dos atores empresas, extrafirma e intermediários envolvidos na constituição das RGP, é importante caracterizar a forma como elas são configuradas e sua gama de relações, sempre reforçando o caráter mutiescalar e a plasticidade funcional dos atores.

A organização da economia em rede não deve ser entendida apenas como uma expressão qualitativa dos fluxos econômicos. Mais do que isso, representa o ponto máximo da economia contemporânea. Porém as diferentes formas que as redes podem apresentar continuam a desafiar os pesquisadores. Coe e Yeung (2015) propõem um ponto de partida para analisar a constituição das redes dentro, entre e além das empresas e das instituições extrafirma. A proposta esboçada pelos autores abrange diferentes possibilidades de mapear a relação entre os atores que constituem as redes de produção e a interseção entre atores e indústrias para formar diferentes setores. Numa primeira observação, Coe e Yeung (2015, p. 59) distinguem duas configurações organizacionais comuns: o modelo de parceria estratégica e o modelo centrado na empresa líder.

No modelo de parceria estratégica, uma empresa líder global assume o papel de parceiro estratégico no provimento de soluções para os produtos e serviços realizados por outras empresas. Há um entrecruzamento de insumos tangíveis e intangíveis na parceria interempresas. Um exemplo desse modelo pode ser encontrado no setor manufatureiro, como o de vestuário, quando o parceiro estratégico assume a responsabilidade de gerir a cadeia de suprimentos de outras empresas, como é o caso da gigante chinesa Li E Fung. No setor de transporte, um parceiro estratégico pode ser o principal fabricante de equipamentos, a exemplo da Boeing e da Airbus (Coe; Yeung, 2015, p. 59). Nesses exemplos, deve-se mencionar que existem inúmeras outras relações com os demais atores da RGP, as quais são incorporadas pelos parceiros estratégicos no trato tanto com operadores logísticos, quanto com organizações trabalhistas e grupos de consumidores, entre outros.

Já no modelo centrado na empresa líder, bastante comum no setor automobilístico, observa-se que uma única empresa domina e dirige inteiramente uma rede de produção para uma parcela significativa de produtores de bens ou serviços. Ao coordenar a ligação com os fornecedores especializados e genéricos para produzir os produtos e bens, a empresa líder prefere internalizar parte do processo produtivo, controlando a qualidade e a entrega das mercadorias para os clientes. 
Os dois modelos têm pontos de conexão e interação, podendo, em muitos casos, se transmutar ao longo do tempo. Um fornecedor especializado de componentes ou serviços pode assumir o papel de parceiro estratégico. Em outra situação, sob a ameaça de um parceiro estratégico, uma empresa líder pode optar por internalizar parte das atividades de fabricação ou todas elas. Das configurações que se formam no interior de uma RGP coordenada por empresas líderes e parceiros estratégicos, outras redes são formadas por múltiplas redes de produção a partir da interseção entre diferentes indústrias. Nesse contexto, Coe e Yeung (2015, p. 62) identificam pelos menos três modelos: (a) agregação: formação de uma indústria, (b) interseção intraindústria e (c) interseções interindústrias.

Esse conjunto de possibilidades, com múltiplas inter-relações entre os atores, forma a base para uma nova arquitetura de poder no interior das redes de produção. Nesse contexto, a ação de cada ator tem como objetivo obter vantagens, visando à criação, ao aprimoramento e à captura do valor.

Na análise da perspectiva da RGP, parte-se do pressuposto de que as redes estão ancoradas em diferentes lugares e regiões e que também operam em múltiplas escalas. $\bigcirc$ espaço representa, de fato, um elemento importante para a constituição e configuração territorial das atividades em rede. Em abordagens anteriores, a economia mundial era dividida basicamente entre países desenvolvidos e em desenvolvimento. A escala nacional representava apenas um container territorial no qual as atividades se realizam, destacadamente o Estado, com sua função regulatória.

problema é que, no período atual, houve uma inserção de muitas regiões na economia mundial, trazendo a questão da competição regional para o cerne do debate. Numa relação de mútua determinação no interior das redes de produção, como é possível aferir localmente o impacto da inserção em RGP? Visto ser a localização extremamente importante para o entendimento da criação do valor, de seu aprimoramento e retenção, na abordagem do que Coe e Yeung (2015) consideram RGP 2.0, o tema da territorialidade é tratado com maior acuidade, a partir de duas dimensões, a vertical e a horizontal.

Na dimensão vertical, a territorialidade compreende múltiplas escalas geográficas ao longo de um contínuo global-local. Existem várias atividades econômicas, cujo escopo espacial é extremamente circunscrito a uma escala específica. Logo, algumas atividades são mais atadas ao local, enquanto outras se entrelaçam à escala supranacional e, num processo de up-scale, há atividades cujo alcance é eminentemente global. Para Coe e Yeung (2015), o global pode ser apenas um dispositivo metafórico para trazer em conjunto todas as escalas, uma vez que nem todas as redes são verdadeiramente globais na sua integração organizacional.

A RGP, portanto, deve ser territorialmente compreendida como um conjunto espacial que reúne atividades de valor regional e localmente centradas. $\bigcirc$ dado novo e relevante diz respeito à interseção entre a dimensão vertical da territorialidade, explicitada acima, e a dimensão horizontal (incorporação lateral do espaço), como resultado de uma maior interação escalar, cujo enraizamento territorial é sua principal marca. Ou seja, tanto pode ocorrer um modelo mais touch down em situações específicas, como também um modelo de interface mais horizontal. 
A seguir, debatem-se as principais vantagens e limitações da proposta RGP, tendo como base as reflexões autocríticas sugeridas pelos próprios proponentes, mediante a discussão e a interlocução acadêmica. Portanto, enfatiza-se um debate interno, muito mais do que uma revisão bibliográfica das críticas ao conceito.

\section{Vantagens e limitações da abordagem das redes globais de produção}

Na seção anterior foram apresentadas a estrutura de organização das RGP ressaltando a questão do valor (e sua trajetória), a caracterização dos atores, as redes e territorialidades e, por fim, as dinâmicas competitivas e estratégicas postas em prática pelos diferentes atores na conformação das redes de produção.

O conceito de RGP vem sendo constantemente renovado, tendo em vista as recentes dinâmicas da economia global, como também o amadurecimento do debate acadêmico não restrito apenas ao campo da geografia econômica. Como foi visto, são muitas as abordagens de análises cognatas, complementares e intercambiáveis. E todas elas têm elementos importantes e que certamente devem ser incorporados à autocrítica e à reflexão sobre o conceito. Para destacar eventuais vantagens do utilizar a estrutura de análise da RGP, apresentam-se alguns aspectos referidos por seus defensores.

Coe, Dicken e Hess (2008) arrolaram pelo menos sete aspectos que merecem atenção: (1) a RGP inclui uma diversidade de atores que participam da conformação das redes de produção, em especial as empresas líderes, mas também outras empresas que exercem múltiplos papéis funcionais, assim como atores extrafirma e atores intermediários, que atuam direta ou indiretamente em diferentes momentos da rede, da produção ao consumo e descarte, (2) é totalmente flexível no uso de múltiplas escalas geográficas, pois não se restringe ou elege como prioridade absoluta, por exemplo, a escala nacional, diferentemente das demais abordagens, (3) reconhece que a natureza e a conexão de uma RGP são diretamente afetadas pelo ambiente do espaço social no qual ela está enraizada, (4) como desdobramento, visa distinguir diferentes tipos de enraizamento, fato esse que leva em conta a origem dos integrantes da rede e sua localização, (5) permite uma avaliação diversificada e clara das relações de poder que compõem a rede, preconizando, portanto, a apreciação mais ampla de formas de governança, (6) permite identificar o valor criado na rede (e para quem), o ponto captado (que pode ser ou não no mesmo local) e como ampliar esse valor e (7) por fim, expande seu escopo, ao identificar potenciais pontos de intervenção e resistência como, por exemplo, as organizações da sociedade civil, movimentos de boicote na arena do consumo e as iniciativas de comércio ético, entre outras ações.

$O$ debate interno entre os autores que adotam a abordagem RGP já incorpora muitas das críticas a ela dirigidas, dando espaço para identificar limitações e lacunas no aprofundamento teórico-metodológico e de aplicação prática em pesquisas realizadas de sua perspectiva.

Entre as principais limitações vislumbradas por Coe (2009), destaca-se a necessidade de estudar o caráter complexo da territorialidade das RGP para entender como empresas, instituições e demais atores não econômicos podem alcançar o desenvolvimento econômico de localidades específicas por meio de um melhor acoplamento estratégico e do uso dos ativos regionais. Não obstante o enfoque da RGP haver contribuído para enfatizar a importância da análise 
interempresas e extrafirma, de organizações estatais e não estatais no interior das RGP, pouca atenção foi dada ao que acontece dentro das empresas, que ainda permanece como uma "caixa-preta", segundo afirma Coe (2009, p. 561).

Outro ponto importante diz respeito às estruturas de governança das RGP. É preciso avançar no entendimento das conexões entre formas de governança e o papel das inovações tecnológicas e organizacionais, cada vez menos emanadas apenas do Estado, mas regidas sobretudo por standards globais. Logo, o modelo RGP deve incrementar seus estudos de modo a identificar os tipos de standards e certificações, bem como sua aplicação em diferentes setores econômicos, países e contextos institucionais. Chama atenção, por exemplo, a recente proliferação de certificações ambientais e sociais, com destaque das relações trabalhistas.

Sobre o mundo do trabalho, há consenso entre muitos autores de que os estudos amparados na RGP precisam apreender melhor a dinâmica geográfica do trabalho (Coe; Dicken; Hess, 2008; Coe, 2009). Não resta dúvida de que os trabalhadores congregam parte fundamental de qualquer rede de produção, mas como tem sido o trabalho de fato analisado nesse esquema interpretativo? Essa é uma questão que ainda carece de melhor apreciação nessa e nas demais formulações (Knorringa; Pegler, 2006; Rainnie; Herod; McGrath-Champ, 2011).

Não obstante a renovação trazida pelo enfoque da geografia do trabalho e seu destaque para a ação dos trabalhadores na transformação da paisagem do capitalismo (Herod, 2001), os mesmos ainda comparecem em muitas análises como "vítimas passivas" da ação do capital. Do contrário, também são destacados apenas os casos de sucesso no conflito estabelecido entre o capital privado e os trabalhadores (Coe; Dicken; Hess, 2008). São urgentes as pesquisas para compreender as diferentes formas de organização da classe trabalhadora em contextos geográficos específicos, mediante a atuação de várias instâncias organizativas da sociedade civil além dos sindicatos e da ação restrita à escala local e que não leva em conta justamente a organização da economia em redes.

Outra lacuna da análise da perspectiva da RGP diz respeito à questão do consumo, aspecto ao qual, segundo Coe, Dicken e Hess (2008, p. 286-287), foi atribuído papel secundário em relação ao da produção. Para os autores, os atos de produção e de consumo vinculados entre si tornaram-se analiticamente indistinguíveis. Mesmo assim, há ainda uma tendência, nos estudos empíricos, a se concentrarem no estágio da produção, influenciados pela suposição de que dela emanam as principais dinâmicas que moldam as redes.

Coe e Yeung (2019, p. 782) identificam alguns temas importantes para a interseção com a teoria das RGP, entre eles, Estado, finanças, trabalho, meio ambiente e desenvolvimento. $\bigcirc$ aprofundamento dessa discussão certamente pode aprimorar futuras agendas de pesquisa sobre o tema.

\section{Considerações finais}

Numa perspectiva histórica, percebe-se claramente o esforço empenhado no conceito de RGP para melhorar o entendimento da dinâmica de organização da economia global. $\bigcirc$ resultado desse esforço pode ser condensado numa tentativa de estabelecer um caminho de análise centrado na agência dos atores, particularmente das empresas líderes e de suas dinâmicas 
competitivas, num escrutínio da trajetória do valor e da conformação de redes e territorialidades. A finalidade máxima, como sempre apregoam seus proponentes, é o desenvolvimento regional e a superação das desigualdades.

Por ser uma proposta conceitual construída da perspectiva da Geografia, é notável a tentativa de seus formuladores de demonstrar que os contextos geográficos, a história e as instituições não podem ser simplesmente postos de lado quando se busca um esquema conceitual de aplicação prática no mundo real. Dito de outro modo, place-to-place variation matters para a natureza e a operação das RGP que interconectam esses lugares (Coe; Yeung, 2015, p. 205).

Há inúmeros desafios para um maior alcance da teoria das RGP, sobretudo no contexto da pandemia do novo coronavírus, que fez se precipitarem muitas tendências de reestruturação produtiva do capital, de algum modo já vislumbradas no horizonte, com implicações diretas e indiretas no funcionamento das RGP. A pandemia da Covid-19 ensejou uma interdição jamais vista na economia global, com a suspensão de muitas redes produtivas organizadas com base na integração, na conectividade e na mobilidade física de bens, mercadorias e pessoas.

Das poucas certezas que se têm no momento, quando há muito mais perguntas que respostas, ressalta-se que o futuro da economia inevitavelmente interpelará algum modo de relação com o espaço, envolvendo o espaço vivido (confinamento de pessoas em suas residências, a casa como local preferencial de compras e de consumo), o espaço das redes (fortalecimento de redes locais, redirecionamento da logística e de redes de fornecimento com prioridade para a escala nacional), as relações de poder econômico expressas no território, as distintas configurações regionais e o novo sentido de global numa mobilidade pós-pandemia.

\section{Referências}

ANTAS JR., R. M. Território e regulação: espaço geográfico como fonte material e não-formal do direito. São Paulo: Humanitas/Fapesp, 2005.

BARRIENTOS, S. Corporate purchasing practices in global production networks: a socially contested terrain. Geoforum, v. 44, p. 44-51, 2013. doi: https://doi.org/10.1016/j. geoforum.2012.06.012.

BEZERRA, J. E. O mercado das certificações nas regiões produtivas do agronegócio da fruticultura. In: ELIAS, D.; PEQUENO, R. (Org.). Tendências da urbanização brasileira: novas dinâmicas de estruturação urbano-regional. Rio de Janeiro: Letra Capital, 2018. v. 1. p. 191-216.

BEZERRA, J. E. Redes de supermercados e a governança do setor agroalimentar: a produção de frutas no Nordeste brasileiro. Ra'e Ga - Espaço Geográfico em Análise, v. 42, p. 104-119, 2017. Disponível em: . Acesso em: 3 jul. 2021

CALLON, M. The sociology of an actor-network: the case of the electric vehicle. In: CALLON, M.; RIP, A.; LAW, J. (Ed.). Mapping the dynamics of science and technology: Sociology of Science in the Real World. Basingstoke, GB: Palgrave Macmillan, 1986. p. 19-34. 
COE, N. M. Advanced introduction to global production networks. Cheltenham, GB: Edward Elgar, 2021.

COE, N. M. Geographies of production II: A global production networks A-Z. Progress in Human Geography, v. 36, n. 3, p. 389-402, 2012. doi: https://doi.org/10.1177/0309132511402784.

COE, N. M. Global production networks. In: KITCHEN, R.; THRIFT, N. (Org.). International Encyclopedia of Human Geography. London: Elsevier, 2009. v. 4. p. 556-562.

COE, N. M.; DICKEN, P.; HESS, M. Global production networks: realizing the potential. Journal of Economic Geography, v. 8, n. 3, p. 271-295, 2008. doi: https://doi.org/10.1093/jeg/lbn002.

COE, N. M.; JORDHUS-LIER, D. Constrained agency? Re-evaluating the geographies of labour. Progress in Human Geography, v. 35, n. 2, p. 211-233, 2011. doi: https://doi.org/10.1177\%2F0309132510366746.

COE, N. M; YEUNG, H. W.-C. Global production networks: mapping recent conceptual developments. Journal of Economic Geography, v. 19, n. 4, p. 775-801, 2019. doi: https://doi.org/10.1093/jeg/lbz018.

COE, N. M; YEUNG, H. W.-C. Global production networks: theorizing economic development in an interconnected world. Oxford: Oxford University Press, 2015.

DICKEN, P. Mudança global: mapeando as novas fronteiras da economia global. Porto Alegre: Bookman, 2010.

DICKEN, P.; KELLY, P. F; OLDS, K.; YEUNG, H. W.-C. Chains and networks, territories and scales: towards a relational framework for analysing the global economy. Global networks, v. 1, n. 2, p. 89-112, 2001. doi: https://doi.org/10.1111/1471-0374.00007.

GEREFFI, G. Global value chains and development: redefining the contours of 21 st century capitalism. Cambridge: Cambridge University Press, 2018.

GEREFFI, G.; KORZENIEWICZ, M.; KORZENIEWICZ, R. P. Introduction. In: GEREFFI, G.; KORZENIEWICZ, M. (Org.). Commodity Chains and Global Capitalism. West Port, CT: Praeguer, 1994. p. 1-15.

GEREFFI, G.; HUMPHREY, J.; KAPLINSKY, R.; STURGEON, T. J. Globalisation, value chain and development. IDS Bulletin, v. 32, n. 3, p. 1-12, 2001. doi:10.1111/j.1759-5436.2001.mp32003001.x.

HENDERSON, J.; DICKEN, P.; HESS, M.; COE, N. M.; YEUNG, H. W.-C. Global production networks and the analysis of economic development. Review of International Political Economy, v. 9, n. 3, p. 436-464, 2002. doi: https://doi.org/10.1080/09692290210150842. 
HEROD, A. Labor geographies: workers and the landscapes of capitalism. New York: Guilford, 2001.

HUGHES, A. Supermarkets and the ethical trade/fair trade movement: making spaces for alternatives food authorities In: LAWRENCE, G.; BURCH, D. (Org.). Supermarkets and agri-food supply chains: transformations in the production and consumption of foods. London: Edward Elgar, 2007. p. 173-191.

JESSOP, B. The State: past, present, future. Cambridge: Polity, 2016.

JÓHANNESSON, G. T.; BAERENHOLDT, J. O. Actor-network/network geographies. In: KITCHEN, R.; THRIFT, N. (Org.). International Encyclopedia of Human Geography. London: Elsevier, 2009. v. 4. p. 15-19.

KAPLINSKY, R.; MORRIS, M. A handbook for value chain research. Institute of Development Studies, University of Sussex, 2001. Disponível em: www.globalvaluechains.org/docs/VchNov01.pdf. Acesso: 13 jul. 2011.

KNORRINGA, P.; PEGLER, L. J. Globalisation, firm upgrading and impacts on labour. Tijdschrift voor Economische en Sociale Geografie, v. 97, n. 5, p. 470-479, 2006. doi: https://doi.org/10.1111/j.1467-9663.2006.00357.x.

LATOUR, B. Reagregando o social: uma introdução à teoria do ator-rede. Salvador/Bauru, SP: Ed. UFBA/Edusc, 2012.

LAW, J. Traduction/trahison: notes on ANT. Lancaster, GB: Lancaster University, 2003.

MAZZUCATO, M. O Estado empreendedor: desmascarando o mito do setor público x setor privado. São Paulo: Portfolio-Penguin, 2014.

NEILSON, L. A. Boycott or buycott? Understanding political consumerism. Journal of Consumer Behaviour, v. 9, n. 3, p. 214-227, 2010. doi: https://doi.org/10.1002/cb.313.

PECK, J.; THEODORE, N. Variegated capitalism. Progress in Human Geography, v. 31, n. 6, p. 731-772, 2007. doi: https://doi.org/10.1177\%2F0309132507083505.

PONTE, S.; GIBBON, P.; VESTERGAARD, J. Governing through standards: origins, drivers and limits. London: Palgrave Macmillan, 2011.

RAIKES, P.; JENSEN, M. F; PONTE, S. Global Commodity chain analysis and the French filière approach: comparison and critique. Economy and Society, v. 29, n. 3, p. 390-417, 2000. doi: https://doi.org/10.1080/03085140050084589.

RAINNIE, A.; HEROD, A.; McGRATH-CHAMP, S. Review and positions: global production networks and labour. Competition $\mathcal{E}$ Change, v. 15, n. 2, p. 155-169, 2011. doi: https://doi.org/10.1179\%2F102452911X13025292603714.

SANTOS, M. A natureza do espaço. 4. ed. São Paulo: Edusp, 2002.

SANTOS, R. S. P. Redes de Produção Globais (RPGs): contribuições conceituais para a pesquisa em ciências sociais. Revista Pós-Ciências Sociais, v. 8, n. 15, p. 127-141, 2011. 
SMITH, A. The state, institutional frameworks and the dynamics of capital in global production networks. Progress in Human Geography, v. 39, n. 3, p. 1-26, 2015. doi: https://doi.org/10.1177\%2F0309132513518292.

SUNLEY, P. Relational economic geography: a partial understanding or a new paradigm? Economic Geography, v. 84, n. 1, p .1-26, 2008. Disponível em: https://www.jstor.org/stable/30033155. Acesso em: 3 jul. 2021.

WILKINSON, J. Sociologia econômica, a teoria das convenções e o fortalecimento dos mercados. Ensaios FEE, Porto Alegre, v. 23, n. 2, p. 805-825, 2002.

Recebido em: 10 jul. 2021 Aprovado em: 29 set. 2021 